\title{
Sensitivity of a Smoke Toxicity Test Method to Test Conditions
}

\author{
NATHAN D. MARSH, RICHARD G. GANN, JASON D. AVERILL and MARC R. NYDEN \\ Building and Fire Research Laboratory \\ National Institute of Standards and Technology \\ Gaithersburg MD 20899
}

\begin{abstract}
Experiments have been conducted in the NFPA 269 / ASTM E1678 radiant apparatus to determine the sensitivity of toxic gas generation to atmospheric oxygen availability and to the conformation of the test specimen. $\mathrm{CO}$ and HCN generation can be dependent on the conformation of the test specimen. Thus, it is important that the test specimen exposure to the radiant source adhere to the likely real-fire exposure of the finished goods. Reducing the initial oxygen volume fraction in the apparatus can affect $\mathrm{CO}$ and $\mathrm{HCN}$ generation, but does not appear to affect the $\mathrm{HCl}$ generation. Fitting the bench-scale test conditions to the full-scale fire ventilation conditions is likely to be important in obtaining good correlations of toxic gas generation.
\end{abstract}

KEYWORDS: product flammability, smoke, toxicity, test methods

\section{INTRODUCTION}

Estimation of the time people will have to escape or find a place of refuge in the event of a fire is a principal component of fire hazard or risk assessment. The tenability of the environment, and therefore the time available to escape or find refuge, is determined primarily by heat and by the spread of fire effluent. The composition of the fire effluent, and therefore its toxicity, is determined by a complex interaction of the chemical composition and burning mode of the materials and finished goods involved in the fire. It is therefore desirable to have a way to determine the products from the burning of these various finished goods, in a manner that reproduces as much as possible the conditions of a real fire.

As regular testing of materials and finished goods at full scale is impractical, numerous reduced-scale test apparatus and methods have been devised so that representative samples, usually on the order of grams in mass or centimeters in size, can be burned and the gaseous products sampled and analyzed. Many of these test methods have provisions so that different fire stages can be simulated. More details can be found in a recent review by ISO/TR 16312-2 [1].

One of these methods, the radiant panel apparatus specified by NFPA 269 [2] and ASTM E1678 [3], attempts to simulate the changing equivalence ratio in a fire environment by maintaining a closed system and allowing the fire gases to recirculate; thus as the sample burns, the air becomes increasingly vitiated. The apparatus accomplishes this via a three-part chimney connecting the combustion chamber to the exposure chamber. The intent is for the fire effluent to travel up the central chimney to the exposure chamber, at the same time driving "fresh" air from the exposure chamber down the outside chimneys to replenish the air in the combustion chamber. The degree to which this approach spans conditions found in real fires is not well understood. Furthermore, the extent of this vitiating process may be affected by sample size, conformation, homogeneity, or material. For example, a relatively small sample will be fully consumed before having a significant effect on its own environment, while a relatively large sample can burn until there is no longer enough oxygen to support combustion. In the standards for the radiant panel apparatus, the guidance for sample size requires the final gas composition in the exposure chamber to be near that which is lethal to half of animals exposed $\left(L C_{50}\right)$ for $30 \mathrm{~min}$. Therefore test specimens that produce extremely toxic products such as HCN will require much smaller sample sizes than those that do not.

Another challenge posed by the most toxic fire products in this test method is that their $L C_{50}$ (30 minute exposure, 14-day post-exposure period) is at or near the detection limit of available instrumentation. For example, $\mathrm{HCN}$ has 30-minute $L C_{50}$ values reported as $135 \mu \mathrm{L} / \mathrm{L}$ and $160 \mu \mathrm{L} / \mathrm{L}$ [4,5]. Quantification of this low volume fraction can be difficult, and therefore accurate determination of both the appropriate sample size, as well as the actual yield of HCN, are impeded. We hypothesize that drawing samples from a location where the fire effluent is more concentrated than in the exposure chamber may improve our ability 
to accurately quantify these potent but low-volume-fraction products. The top of the central chimney is identified as one such location.

In this work, we report the tests of three canonical materials-a vinyl veneer particleboard, a cotton/polyester fabric over a polyurethane foam, and a polyvinyl chloride (PVC) clad 3-conductor electrical cable - using this radiant panel apparatus. The test specimens are cut from the finished goods burned in previous full-scale tests [6] (sofa mock ups, particleboard bookcases, and trays of PVC clad electrical cables), so that the results of the full-scale tests could be compared to those found here. Gas samples were drawn from both the normal location in the exposure chamber and also from the top of the center chimney for analysis. In order to determine the effect of oxygen consumption, tests were also carried out where the initial oxygen volume fraction in the apparatus was reduced to $17 \%$. This value was chosen for being low enough to produce a noticeable effect, while still allowing flaming combustion of the specimens. It is considered representative of a typical post-flashover environment, for which data were also recorded in the full-scale tests. Finally, in order to determine the importance of specimen inhomogeneity (e.g., due to layering of the component materials), each of these materials was also tested after having been diced, i.e., cut into pieces with sizes on the order of $1 \mathrm{~cm}$.

\section{EXPERIMENTAL EQUIPMENT AND PROCEDURES}

\section{Radiant Panel Apparatus NFPA 269 and ASTM E1678}

The radiant panel apparatus, depicted in Fig. 1, consists of three main parts: 1) The sample combustion chamber, consisting of a $13 \mathrm{~cm}$ diameter $32 \mathrm{~cm}$ long quartz cylinder, with an electronic load cell on which the sample is placed, two linear parabolic quartz heating elements at 45 degree angles to the surface of the sample, and a spark igniter; 2) a three-part chimney above the sample combustion chamber allowing the movement of fire effluent up the center chimney and the recirculation of "fresh" air down the outside chimneys; and 3) a $0.2 \mathrm{~m}^{3}$ exposure chamber attached to the top of the chimney, including a circulating fan and six ports originally provided for animal exposure.

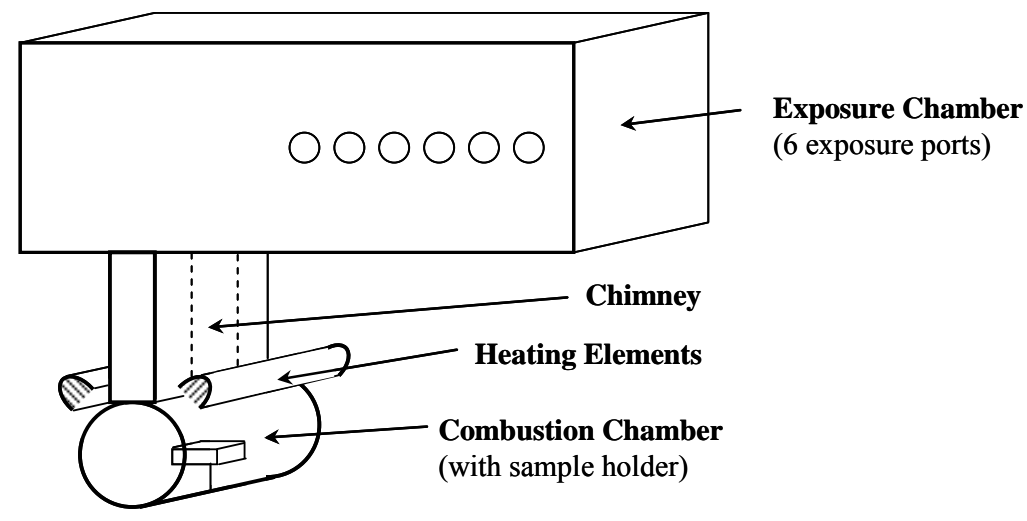

Fig. 1. Radiant panel apparatus.

Test specimens are placed in the sample holder in the sample combustion chamber, which is then closed. The quartz heating elements, set to provide $50 \mathrm{~kW} / \mathrm{m}^{2}$ at the sample surface, are turned on, as is the spark igniter. Once flames are observed the spark is turned off. In a modification of the standard operating procedure, for this paper the heating elements were turned off and the smoke shutter closed when flaming ceased. At the same time, the combustion chamber was flushed with nitrogen to quench all reactions. This modification was intended to more accurately model the full-scale tests, where there is no sustained external heating of the burning finished goods. Otherwise, charring materials would continue to produce large amounts of $\mathrm{CO}$ after the end of flaming from oxidative pyrolysis.

\section{Tested Samples}

Test specimens from the three finished goods were burned as intact specimens and diced, i.e., cut into centimeter sized pieces. The intact particleboard specimen was $7.5 \mathrm{~cm}$ by $10 \mathrm{~cm}$ by $1 \mathrm{~cm}$ thick with the vinyl veneer on the upper (exposed) surface. The intact polyurethane foam specimen was $7.5 \mathrm{~cm}$ by $7.5 \mathrm{~cm}$ 
by $1 \mathrm{~cm}$ thick with a $7.5 \mathrm{~cm}$ by $7.5 \mathrm{~cm}$ sheet of cotton/polyester fabric on the upper (exposed) surface. The intact cable specimens consisted of 3 lengths of $13 \mathrm{~cm}$ each arranged side-by-side. In the diced configuration, the particleboard and foam were cut into centimeter-sized cubes and randomly arranged in the sample holder, while the cable was cut into lengths less than $1 \mathrm{~cm}$ and the insulating materials separated. In each case the quantity of material was the same mass as that used in the intact specimen (approximately $90 \mathrm{~g}, 6 \mathrm{~g}$, and $30 \mathrm{~g}$ for the particleboard, foam, and cable, respectively.) Sample sizes were chosen to produce a Fractional Effective Dose (FED) near 1, as determined by the N-gas model [7]:

$$
\begin{aligned}
& F E D=\frac{m \cdot \varphi_{\mathrm{CO}}}{\varphi_{\mathrm{CO}_{2}}-b}+\frac{21 \%-\varphi_{\mathrm{O}_{2}}}{21-L C_{50} \mathrm{O}_{2}}+\frac{\varphi_{\mathrm{HCN}}}{L C_{50} \mathrm{HCN}}+\frac{\varphi_{\mathrm{HCl}}}{L C_{50} \mathrm{HCl}}+\frac{\varphi_{\mathrm{HBr}}}{L C_{50} \mathrm{HBr}} \\
& =\frac{m \cdot \varphi_{\mathrm{CO}}}{\varphi_{\mathrm{CO}_{2}}-b}+\frac{21 \%-\varphi_{\mathrm{O}_{2}}}{21 \%-5.4 \%}+\frac{\varphi_{\mathrm{HCN}}}{150 \mu \mathrm{L} / \mathrm{L}}+\frac{\varphi_{\mathrm{HCl}}}{3700 \mu \mathrm{L} / \mathrm{L}}+\frac{\varphi_{\mathrm{HBr}}}{3000 \mu \mathrm{L} / \mathrm{L}}
\end{aligned}
$$

$\varphi_{x}$ is the volume fraction of gas $\mathrm{x}$, in $\mathrm{L} / \mathrm{L}$ for $\mathrm{CO}_{2}$ and $\mathrm{O}_{2}$, and in $\mu \mathrm{L} / \mathrm{L}$ for the other gases above. $m$ and $b$ are empirically determined constants such that if $\varphi_{\mathrm{CO}_{2}}<5 \%$ then $m=-18$ and $b=122,000$; whereas if $\varphi_{\mathrm{CO} 2}>5 \%$ then $m=23$ and $b=-38,600$.

Table 1 lists the mass lost for each specimen type, configuration, and initial oxygen volume fraction, averaged over several tests. Uncertainties are the standard deviations of those tests and represent the runto-run variation.

Table 1. Mass Lost from Burning Specimens

\begin{tabular}{ccccc}
\hline $\begin{array}{c}\text { Specimen } \\
\text { Configuration }\end{array}$ & $\begin{array}{c}\mathbf{O}_{2} \text { Volume } \\
\text { Fraction } \\
(\mathbf{L} / \mathbf{L})\end{array}$ & $\begin{array}{c}\text { Particleboard } \\
\text { Mean Mass } \\
\text { Loss (g) }\end{array}$ & $\begin{array}{c}\text { Cushion } \\
\text { Materials Mean } \\
\text { Mass Loss (g) }\end{array}$ & $\begin{array}{c}\text { Electrical } \\
\text { Cable Mean } \\
\text { Mass Loss (g) }\end{array}$ \\
\hline Whole Slab & 0.21 & $25.9 \pm 2.5$ & $5.4 \pm 0.3$ & $7.9 \pm 0.3$ \\
Whole Slab & 0.17 & $16.6 \pm 2.3$ & $5.4 \pm 0.3$ & $8.1 \pm 0.3$ \\
Diced & 0.21 & $24.6 \pm 1.1$ & $5.5 \pm 0.1$ & $7.8 \pm 0.4$ \\
Diced & 0.17 & $17.4 \pm 1.4$ & $5.6 \pm 0.2$ & $7.2 \pm 0.5$ \\
\hline
\end{tabular}

\section{Gas Analysis}

$\mathrm{CO}$ and $\mathrm{CO}_{2}$, were quantified using a non-dispersive infrared (NDIR) gas analyzer; oxygen was quantified by a paramagnetic analyzer in the same instrument. Gas was continuously drawn from the exposure chamber by a small pump and passed through a series of traps and filters, first a coiled tube immersed in a water ice bath, then an impinger bottle immersed in dry ice, with its upper half filled with glass wool, and finally a glass fiber disk filter. The intent was to remove particulates and condensable species, including water, that would otherwise interfere with and possibly harm the analyzer. While sampling, the flow was maintained at $1 \mathrm{~L} / \mathrm{min}$ for the $\mathrm{CO}$ and $\mathrm{CO}_{2}$ detectors and $0.2 \mathrm{~L} / \mathrm{min}$ for the $\mathrm{O}_{2}$ detector. The analyzer itself was calibrated daily with zero and span gases (a mixture of $5000 \mu \mathrm{L} / \mathrm{L} \mathrm{CO}$ and $0.08 \mathrm{~L} / \mathrm{L}$ of $\mathrm{CO}_{2}$ in nitrogen, and ambient air ( $0.2095 \mathrm{~L} / \mathrm{L}$ oxygen on a dry basis)).

$\mathrm{HCN}, \mathrm{HCl}$, and $\mathrm{HBr}$ were quantified using a Fourier Transform Infrared (FTIR) Spectrometer, equipped with a stainless steel flow cell with $2 \mathrm{~mm} \mathrm{KBr}$ windows and a $0.1 \mathrm{~m}$ pathlength, maintained at $170{ }^{\circ} \mathrm{C}$. Samples were drawn through heated $0.635 \mathrm{~cm}(1 / 4 \mathrm{inch})$ copper tubes from two locations: at the center of the chimney approximately $7 \mathrm{~cm}$ below the top, and from a fitting mounted in one of the animal exposure ports at approximately the same location as the sampling line for the NDIR. Switching between sampling locations was accomplished by rotating a T-valve fitting that was connected, via more heated copper tube, to the flow cell. The sample was pulled through the sampling lines and flow cell by a small pump located downstream from the flow cell, and then returned to the exposure chamber in order to minimize the effect of gas removal on the contents of the chamber. The pump flow was measured at $10 \mathrm{~L} / \mathrm{min}$ maximum, but 
was at times lower due to fouling of the sampling lines with smoke deposits. In a typical run, gas was sampled from the chimney from the start of the test until the flame was determined to have gone out. At this point the T-valve was rotated to sample from the exposure chamber.

The signal to noise ratio was also improved by averaging up to several hundred spectra prior to quantification. An example of a spectrum resulting from this procedure is shown in Fig. 2. Using these spectra, $\mathrm{HCN}, \mathrm{HCl}$, and $\mathrm{HBr}$ were quantified using the Autoquant software. This is a software package for performing real time and off-line quantitative analyses of target compounds, and is based on the Classical Least Squares (CLS) algorithm as described by Haaland, et. al [8]. In this method, the measured spectra are fit to linear combinations of reference spectra corresponding to the target compounds.

Calibration spectra were obtained from a quantitative spectral library assembled by Midac [9] and from a collection of spectra provided the Federal Aviation Administration who performed bench-scale fire tests on similar materials [10]. In this analysis, the least squares fits were restricted to characteristic frequency regions or windows for each compound that were selected in such a way as to maximize the discrimination of the compounds of interest from other components present in fire gases. Table 2 lists the species included in this analysis and the frequency windows used for their quantification. Other species including $\mathrm{HBr}$, acetylene, and acrolein were initially included in the analysis, but after the careful examination of the spectra recorded in the experiments, it was determined that they are not present in measurable quantities. Although $\mathrm{CO}$ and $\mathrm{CO}_{2}$ are not quantified by this method, they are included in the analysis so that their presence does not produce "false positives" in other species that absorb in the same frequency regions. All reference spectra were recorded at $170{ }^{\circ} \mathrm{C}$ and ambient pressure.

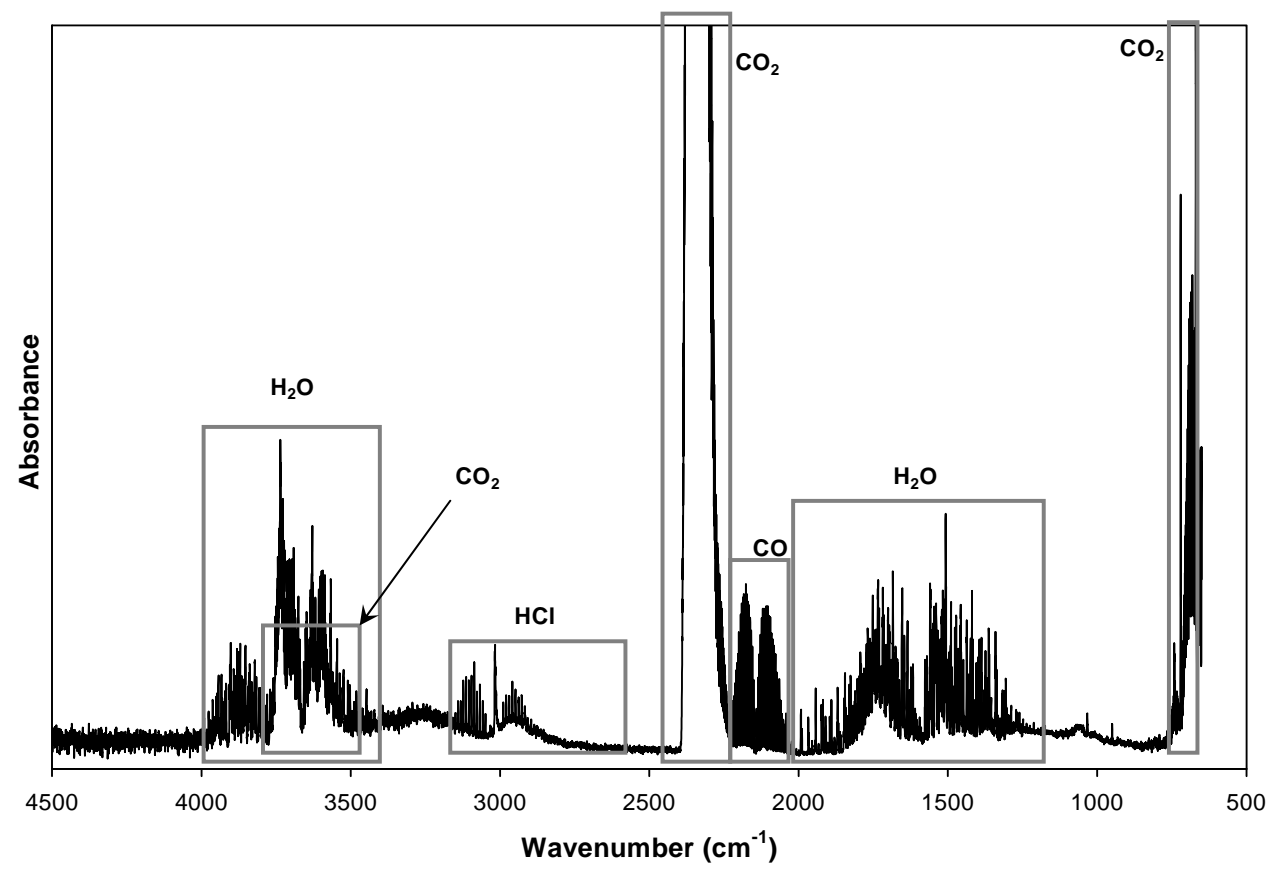

Fig. 2. FTIR spectrum of the products of burning electrical cable. 
Table 2. Species and Frequency Windows for FTIR Analysis.

\begin{tabular}{cccc}
\hline Compound & $\begin{array}{c}\text { Reference } \\
\text { Volume Fraction } \\
(\boldsymbol{\mu L} / \mathbf{L})\end{array}$ & $\begin{array}{c}\text { Frequency } \\
\text { Window }\left(\mathbf{c m}^{-\mathbf{1}}\right)\end{array}$ & $\begin{array}{c}\text { Minimum } \\
\text { Detection } \\
\text { Limit }(\boldsymbol{\mu L} / \mathbf{L})\end{array}$ \\
\hline $\mathrm{CH}_{4}$ & 483 & 2800 to 3215 & $\mathrm{NA}^{\mathrm{a}}$ \\
$\mathrm{CO}$ & 2410 & 2050 to 2225 & 50 \\
$\mathrm{H} \mathrm{H}_{2}$ & 100,000 & 1225 to 2150,3400 to 4000 & $\mathrm{NA}^{\text {a }}$ \\
$\mathrm{HCl}$ & 9870 & 2600 to 3100 & 50 \\
$\mathrm{HCN}$ & 507 & 710 to 722,3200 to 3310 & 50 \\
$\mathrm{CO}_{2}$ & 47,850 & 660 to 725,2230 to 2300,3500 to 3760 & 50 \\
\hline
\end{tabular}

${ }^{a}$ Because these compounds do not contribute to toxicity, their minimum detection limits were not quantified

\section{Quantification of HCN}

As mentioned previously, one of the difficulties in quantifying $\mathrm{HCN}$ is that its 30 -minute $L C_{50}$ value $(150 \mu \mathrm{L} / \mathrm{L}$ in the $\mathrm{N}$-gas model [7]) is only a few times the minimum detection limit in this instrument. Therefore, an alternate method was employed in order to increase the signal, namely sampling gas from the chimney, where smoke gas volume fractions were expected to be significantly higher than they were in the exposure chamber. Assuming that the smoke gas undergoes no further chemistry beyond the chimney sampling location, the volume fraction of a more easily quantifiable gas such as $\mathrm{CO}_{2}$ in both the chimney and the exposure chamber can be used to determine the degree of dilution.

Ideally, we would wish to integrate the flow of both the reference gas and HCN past the chimney sampling port and divide the total by the exposure chamber volume. However, because the test apparatus is designed to recirculate gas from the exposure chamber to the combustion chamber, an unknown fraction of the gas passing the chimney sampling port is from the exposure chamber rather than the sample, having already been "counted" on a previous trip up the chimney. So instead, we used the average volume fractions in the chimney over the course of the sample burn, and then related this to the final volume fraction in the exposure chamber.

\section{RESULTS}

\section{Particleboard}

Figure 3 shows the resulting gas volume fraction profiles from four similar particleboard tests. Each test used a $7.5 \mathrm{~cm}$ by $10 \mathrm{~cm}$ by $1 \mathrm{~cm}$ thick slab with the vinyl veneer on the exposed surface. The progress of each test has been normalized by the extent of the burn. The justification for normalizing by the extent of burn is to depict the repeatability of the test. If profiles generally match, this indicates that the specimens burned in a consistent manner. If, on the other hand, profiles vary widely, as they do for $\mathrm{CO}$ in Fig. 3, this indicates a high variation from test to test. In this particular case, we attribute the variation of $\mathrm{CO}$ to the tendency of the particleboard to transition unpredictably from flaming to smoldering, at which point $\mathrm{CO}$ production dominated. Although our test procedure extinguishes the reaction and isolates the exposure chamber once the flame dies, these data indicate the need to close the smoke shutter promptly and repeatably to mitigate the measurable production of $\mathrm{CO}$ from smoldering.

The depiction of volume fraction profiles shown in Fig. 3 does not allow for easy comparison to other tests with different materials or conditions. Therefore subsequent figures show average profiles combining two or more tests of the same kind, using the following procedure. The data from a given test are rescaled so that the mass loss entries occur at regular intervals. Then, for a given mass loss $\%$, the volume fraction entries are averaged across multiple tests of the same type, and standard deviations taken. In the subsequent figures, the bold line represents the average of multiple tests and the lighter lines represent one standard deviation above and below that average. 


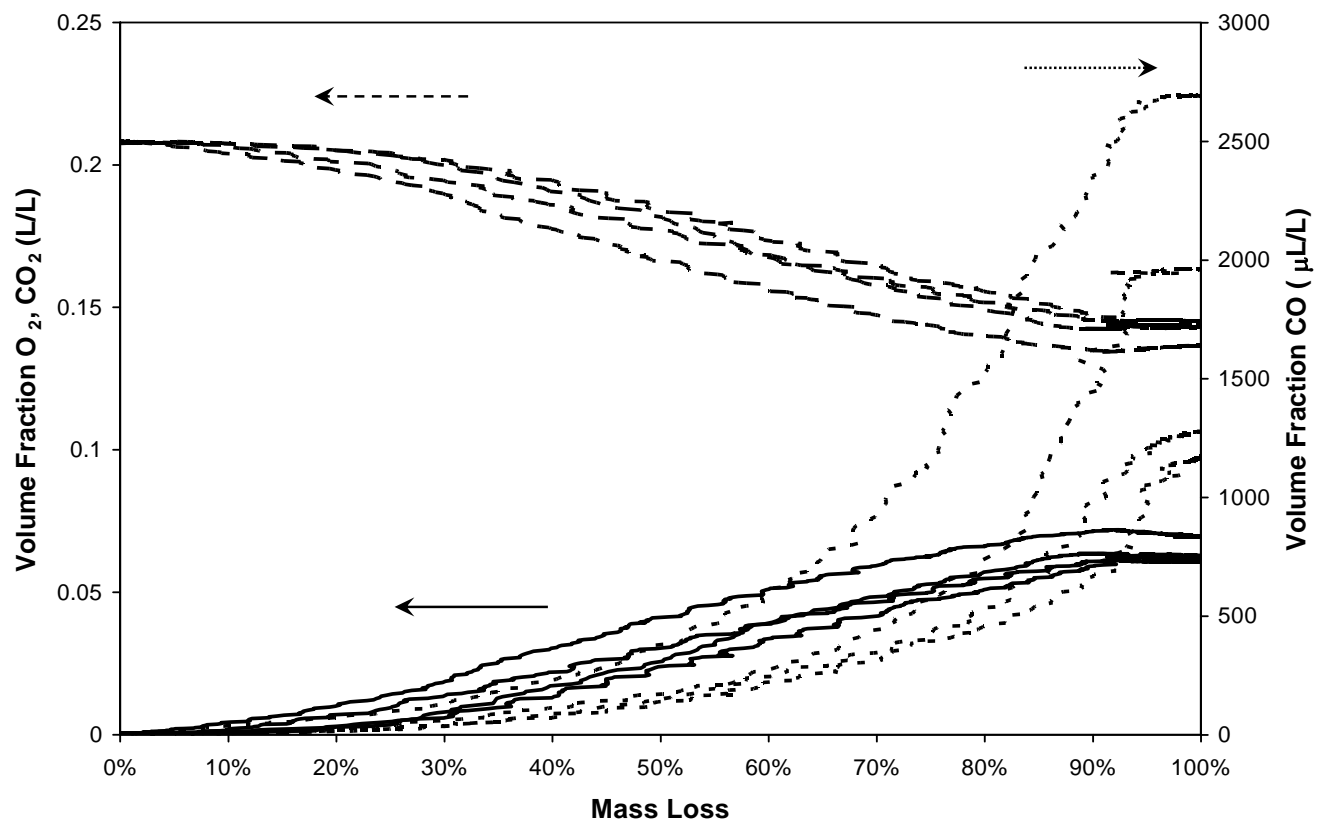

Fig. 3. Gas volume fractions from four particleboard tests. (Solid, $\mathrm{CO}_{2}$; dotted, $\mathrm{CO}$; dashed, $\mathrm{O}_{2}$ ).

So, for example, in Fig. 4 we combine the results of four tests with an initial oxygen volume fraction of $21 \%$ (solid lines) to results from two tests with an initial oxygen volume fraction of $17 \%$ (dotted lines), all using $7.5 \mathrm{~cm}$ by $10 \mathrm{~cm}$ by $1 \mathrm{~cm}$ thick slabs of particleboard. Most significantly, although the oxygen volume fractions were different at the start of the two sets of tests, by the end they were nearly the same. This implies that the particleboard burning is an oxygen-limited process and that once the oxygen volume fraction drops below $\approx 15 \%$, burning in the flaming mode ceases. If flaming is limited by a lack of oxygen, then the overall effect of reducing the initial oxygen volume fraction is to reduce the overall intensity of burning - a view supported by the reduction in $\mathrm{CO}_{2}$ production when the initial oxygen volume fraction was reduced, as seen in Fig. 4. The production of $\mathrm{CO}$ in the same sets of tests, shown in Fig. 5, was also reduced when the initial oxygen volume fraction was reduced. In summary, lower initial oxygen gave less complete combustion, as expected. The difference was small, since the test specimens approached flame extinction as they approached the same residual oxygen volume fraction.

In these tests, the FEDs based on the volume fractions when progress reaches a mass loss of $100 \%$ are 0.83 and 0.74 for oxygen volume fractions of $21 \%$ and $17 \%$ respectively. (These values are slightly higher than those computed for the $30 \mathrm{~min}$ exposure because over the course of those 30 minutes the falling temperature of the air allows the apparatus expansion bag to deflate, which introduces air that was sequestered from the recirculating and burning process.) The change in FED is primarily the result of a reduction in $\mathrm{CO}$, although the contribution from oxygen depletion actually rises slightly. These values are well in the range specified by the standard ( 0.5 to 1.5$)$; if they were not, it is uncertain whether the method of adjusting the sample size would be able to compensate. If the burning of the particleboard material in this apparatus is in fact oxygen-limited, then a larger sample would experience the same absolute mass loss as a smaller sample, in both cases burning only until the oxygen volume fraction reaches $\approx 14 \%$ and producing identical quantities of $\mathrm{CO}$ and $\mathrm{CO}_{2}$ as were found here. 


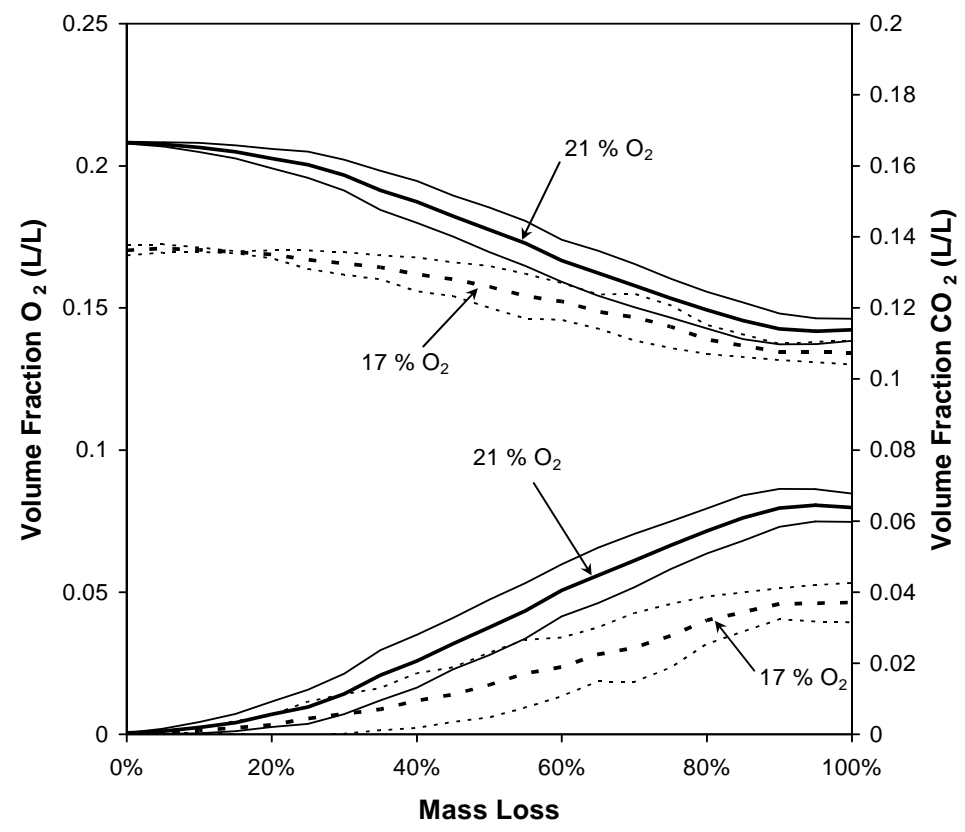

Fig. 4. Comparison of oxygen consumption (top half of figure) and $\mathrm{CO}_{2}$ production (bottom half of figure) in particleboard tests at oxygen volume fractions of $21 \%$ (solid lines) and $17 \%$ (dotted lines).

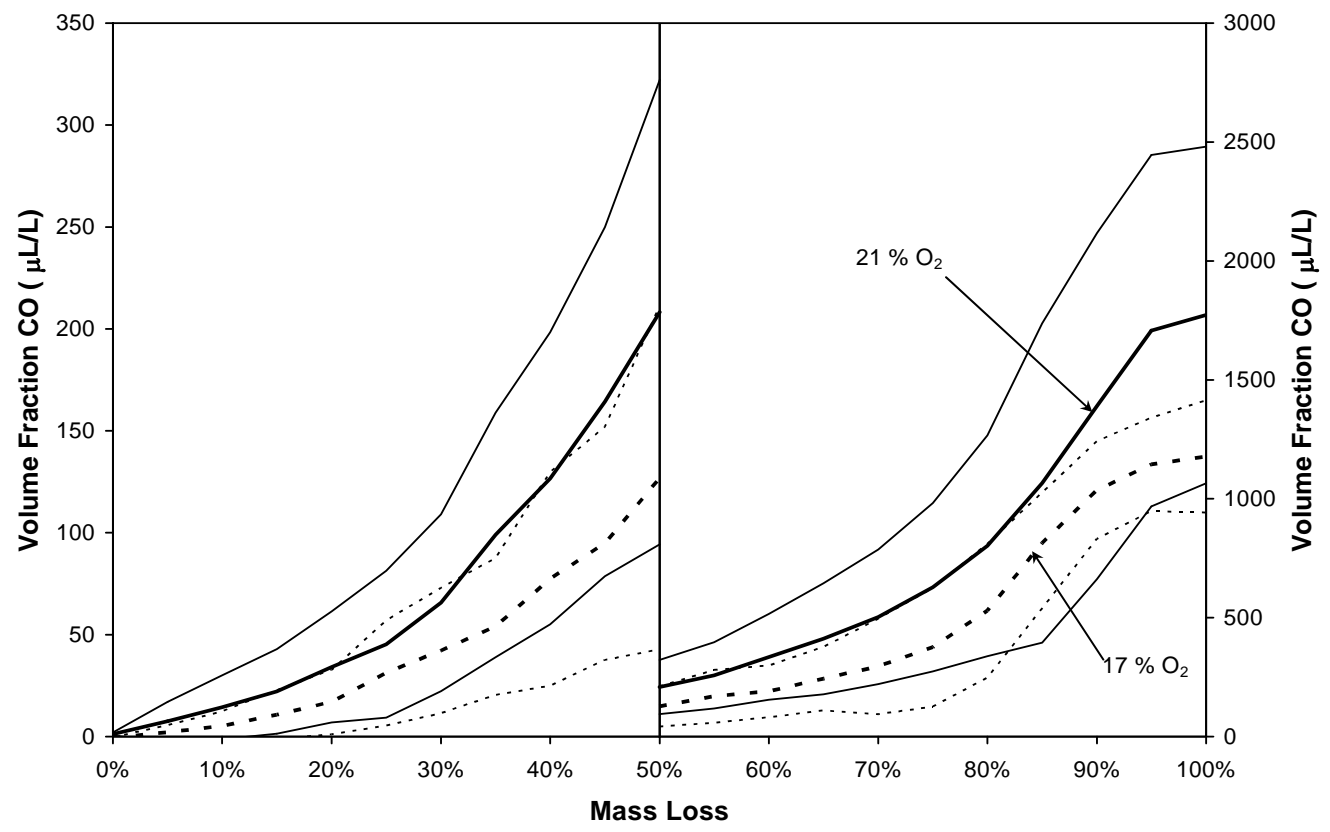

Fig. 5. Comparison of CO production in particleboard tests with oxygen volume fractions of $21 \%$ (solid lines) and $17 \%$ (dotted lines). Note the change of ordinate scale at mass loss of $50 \%$.

Figure 6 compares the effect of dicing the particleboard, depicting the $\mathrm{CO}$ production as a function of mass loss fraction. The primary observation from this comparison is that dicing the material serves to reduce the scatter of the results at all stages, as indicated by the much narrower standard deviation bands. And although it appears that at earlier stages of burning the CO production was lower in the diced configuration, 
it ultimately reached the same value in either case. An analysis of the production of $\mathrm{CO}_{2}$ and oxygen shows essentially the same trend - reduced scatter but ultimately reaching the same average value.

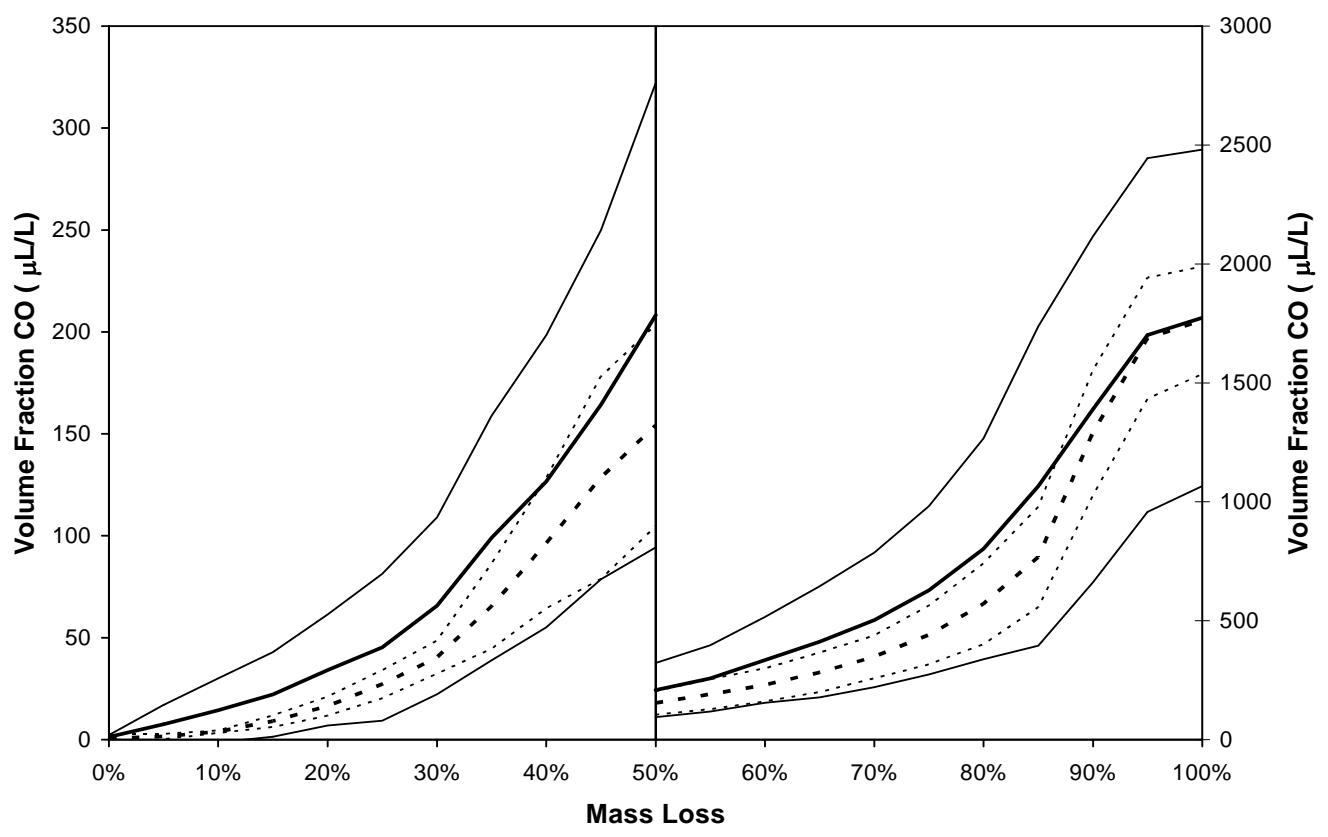

Fig. 6. Comparison of CO production in particleboard tests in slab (solid lines) and diced (dotted lines) configurations. Note the change of ordinate scale at mass loss of $50 \%$.

\section{Electrical Cable}

A similar, but not identical behavior was found in the burning of diced and whole electrical cable. As shown in Fig. 7, the diced electrical cable specimens do appear to have produced less $\mathrm{CO}$ in the early stages of burning, but ultimately the exposure chamber $\mathrm{CO}$ volume fraction reached the same value as when the cables were whole. However, unlike in the particleboard tests, dicing the electrical cables significantly expanded the standard deviation of the measured $\mathrm{CO}$ volume fractions in the later stages of burning. We hypothesize that this difference can be explained by the way dicing transformed the test specimen. In the case of the particleboard, the ignition of the whole slab depended on the behavior of the veneer, which peeled and blistered in an irregular way, changing the initial heat flux to the underlying wood. Dicing the particleboard significantly reduced the exposure of the veneer; the primary exposure in that case was the homogenous wood particle matrix. The cable, on the other hand, is composed of multiple layers including the PVC outer sheath, paper wrappers, individual conductor insulators, and the copper conductors. In the whole configuration, these layers melted and burned in turn, and presented a spatially uniform material facing the radiant heaters. In the diced configuration, the cables consisted of a randomly-ordered array of $1 \mathrm{~cm}$ pieces of four or five different materials. This approach does not allow for strict control of the material distribution across the sample holder. Whereas dicing the particleboard reduced its disorder to the scale of the wood particles, dicing the cable increased disorder to the $1 \mathrm{~cm}$ scale. 


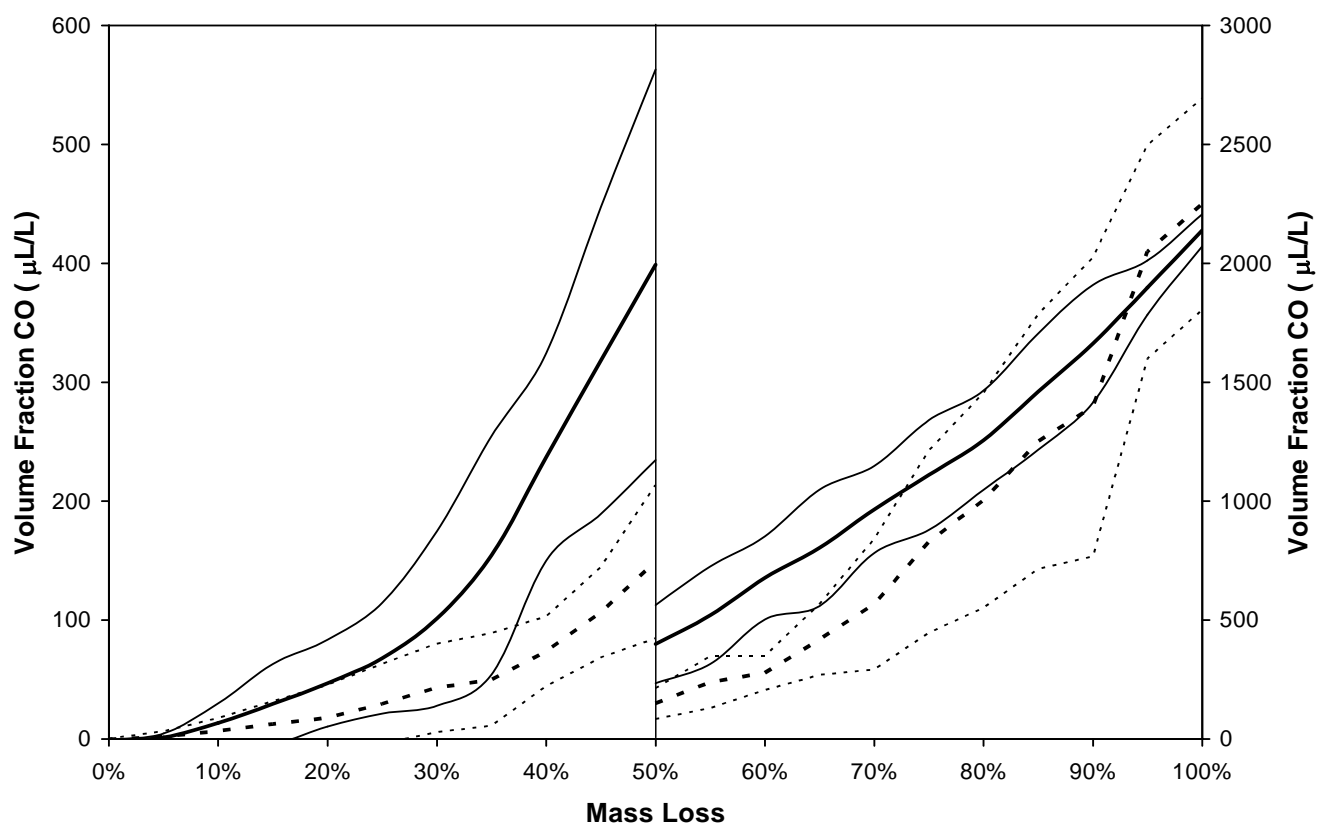

Fig. 7. Comparison of $\mathrm{CO}$ production in electrical cable tests in whole (solid lines) and diced (dotted lines) configurations. Note the change of ordinate scale at mass loss of $50 \%$.

\section{Cushion Materials}

The third set of specimens examined here, the fabric/foam combinations, was by comparison not sensitive to either configuration or initial oxygen volume fraction. Fig. 8 shows the oxygen depletion and $\mathrm{CO}_{2}$ production from tests of whole slabs of foam with initial oxygen volume fractions of $21 \%$ and $17 \%$. Unlike the particleboard, the foam did not appear to be limited by oxygen consumption. The oxygen depletion in either case was essentially the same. However, even in the reduced oxygen tests, the oxygen volume fraction never fell to $14 \%$, the limiting volume fraction for the particleboard. One reason for this low oxygen depletion was the small size of the foam specimen ( $6 \mathrm{~g}$ compared to $90 \mathrm{~g}$ of particleboard.) Therefore a larger specimen of polyurethane foam might experience some effect from a reduced oxygen test, or if there were a larger reduction in the initial volume fraction. It should be noted that the reduced oxygen tests did have an effect on CO production, increasing its volume fraction from $500 \mu \mathrm{L} / \mathrm{L}$ to 750 $\mu \mathrm{L} / \mathrm{L}$.

Another feature of the polyurethane foam tests was the brief duration of the flaming mode, lasting for under $1 \mathrm{~min}$ in most cases, compared to $2.5 \mathrm{~min}$ for the cable and 2 to $5 \mathrm{~min}$ for the particleboard. From Fig. 8 it appears that both the oxygen consumption and the $\mathrm{CO}_{2}$ generation were confined to the later stages of mass loss, behavior not seen with the other materials. We suspect that this is primarily a result of a delay on the order of 10s of seconds between the burning of the sample material, the propagation of the effluent into the exposure chamber, and finally to the instrument, that is masked by the longer duration of the flaming mode of the other materials. However, it is also possible that a delay exists between the gasification of the foam and the oxidation of those gases.

\section{Effect of Initial Oxygen Volume Fraction and Specimen Dicing on $\mathrm{HCl}$ and HCN Production}

In addition to the measurement of the gases already discussed, additional toxic and irritant gases were quantified by FTIR. Although a number of gases were monitored (see Table 2), we ultimately only observed $\mathrm{HCl}$ from burning cables and $\mathrm{HCN}$ from burning polyurethane foam. As these are important gases in the N-gas model, we attempted to improve their quantification by measuring their volume fraction from multiple locations. Therefore gas for FTIR analysis was sampled both from the exposure chamber and from the top of the chimney. As described in the Experimental section, interpretation of the volume fraction measured at the chimney is ambiguous. Instead, we used the volume fraction of $\mathrm{CO}_{2}$ measured at 
both the chimney and the exposure chamber as a measure of dilution, and then applied the same dilution factor to extrapolate exposure chamber volume fractions for $\mathrm{HCl}$ and $\mathrm{HCN}$. These volume fractions are presented in Table 3 and Table 4.

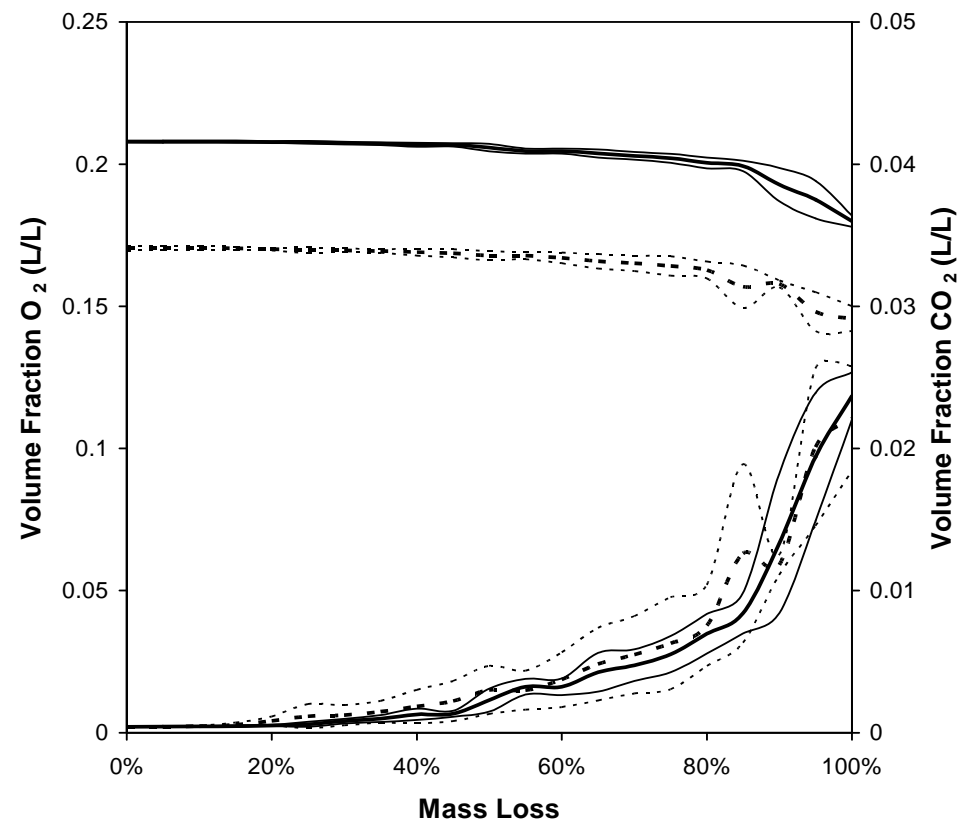

Fig. 8. Comparison of oxygen consumption (top half of figure) and $\mathrm{CO}_{2}$ production (bottom half of figure) in polyurethane foam tests at oxygen volume fractions of $21 \%$ (solid lines) and $17 \%$ (dotted lines).

Table 3. Measured and extrapolated 30-minute mean volume fractions of $\mathrm{HCl}$ in the exposure chamber from burning electrical cables. Values are averages of several tests.

\begin{tabular}{lccccc}
\hline Configuration & $\begin{array}{c}\mathbf{O}_{2} \text { Volume } \\
\text { Fraction } \\
(\mathbf{L} / \mathbf{L})\end{array}$ & $\begin{array}{c}\text { Measured Mean } \\
\text { HCl Volume } \\
\text { Fraction }(\boldsymbol{\mu L} / \mathbf{L})\end{array}$ & $\begin{array}{c}\text { Standard } \\
\text { Deviation } \\
(\boldsymbol{\mu} \mathbf{L} / \mathbf{L})\end{array}$ & $\begin{array}{c}\text { Extrapolated } \\
\text { Mean HCl } \\
\text { Volume Fraction } \\
(\boldsymbol{\mu L} / \mathbf{L})\end{array}$ & $\begin{array}{c}\text { Standard } \\
\text { Deviation } \\
(\boldsymbol{\mu} \mathbf{L} / \mathbf{L})\end{array}$ \\
\hline Whole Cables & 0.21 & 2700 & 1400 & 4700 & 1000 \\
Whole Cables & 0.17 & 3900 & 70 & 6500 & 150 \\
Diced & 0.21 & 3800 & 1200 & 6300 & 1800 \\
Diced & 0.17 & 4700 & 200 & 6400 & 400 \\
\hline
\end{tabular}

Table 4. Measured and extrapolated 30-minute mean volume fractions of $\mathrm{HCN}$ in the exposure chamber from burning polyurethane foam. Values are averages of several tests.

\begin{tabular}{lccccc}
\hline Configuration & $\begin{array}{c}\mathbf{O}_{2} \text { Volume } \\
\text { Fraction } \\
(\mathbf{L} / \mathbf{L})\end{array}$ & $\begin{array}{c}\text { Measured Mean } \\
\text { HCN Volume } \\
\text { Fraction }(\boldsymbol{\mu L} / \mathbf{L})\end{array}$ & $\begin{array}{c}\text { Standard } \\
\text { Deviation } \\
(\boldsymbol{\mu L} / \mathbf{L})\end{array}$ & $\begin{array}{c}\text { Extrapolated } \\
\text { Mean HCN } \\
\text { Volume Fraction } \\
(\boldsymbol{\mu L} / \mathbf{L})\end{array}$ & $\begin{array}{c}\text { Standard } \\
\text { Deviation } \\
(\boldsymbol{\mu L} / \mathbf{L})\end{array}$ \\
\hline Whole Slab & 0.21 & 30 & 50 & 70 & 90 \\
Whole Slab & 0.17 & 30 & 20 & 30 & 50 \\
Diced & 0.21 & 90 & 40 & 140 & 30 \\
Diced & 0.17 & 60 & 30 & 140 & 70 \\
\hline
\end{tabular}


From these results, we do not find that any discernable pattern emerges regarding the effect of configuration or oxygen volume fraction on the production of $\mathrm{HCl}$ or $\mathrm{HCN}$ from these materials. However, the extrapolated gas volume fractions are consistently higher than the measured ones. One possible explanation is that as the gases dilute and cool, wall deposition is occurring between the chimney and the exposure chamber. Another is that the gases are continuing to react past the chimney sampling location; the $\mathrm{HCN}$ and $\mathrm{HCl}$ could experience consumption after the chimney, or additional $\mathrm{CO}_{2}$ could form. In the latter case, the additional unquantified $\mathrm{CO}_{2}$ would cause us to underestimate the dilution factor, which in turn would cause us to overestimate the volume fraction in the exposure chamber. The possibility of additional reactions is supported by our observation that in some tests we observed flames exiting the top of the chimney. In any event, it does not appear that this extrapolation method reduces the uncertainty in the quantification of $\mathrm{HCl}$ and $\mathrm{HCN}$.

\section{SUMMARY AND CONCLUSIONS}

The NFPA 269 and ASTM E1678 radiant panel apparatus is an important tool for evaluating the composition and toxicity of gases from the combustion of samples representative of finished goods. In this work, we examined the significance of oxygen volume fraction and sample geometry and homogeneity, and attempted to improve the quantification of lower-volume-fraction toxic and irritant gases. We find that for larger samples, the initial oxygen volume fraction can affect the quenching or burnout behavior of the sample, potentially having an effect on the gases evolved, but that for smaller samples the effect is limited. We also find that if cutting a sample into small pieces increases uniformity of the exposed surface, this can increase the repeatability of the tests; however, depending on the construction of the sample, cutting it into small pieces may actually decrease surface uniformity and therefore decrease the repeatability of the tests. Finally, we find that quantifying low-volume-fraction gases remains a challenge and that uncertainties (as measured by the standard deviation of repeat tests) remain on the order of the measured value. A possible solution may be to relax the requirement that the gas composition be near the $L C_{50}$ for 30-minute exposure, and burn larger samples of materials that produce highly toxic gases in low volume fractions, as these materials are also less sensitive to oxygen volume fraction.

Key points:

o The flaming of the high mass test specimens appeared to extinguish when the oxygen volume fraction approaches $14 \%$. A low mass test specimen can burn out before depleting the oxygen volume fraction to that value.

o $\mathrm{CO}$ and HCN generation can be dependent on the conformation of the test specimen. At present, there is no method for predicting the magnitude of the effect. Thus, it is important that the test specimen exposure to the radiant source adhere to the likely real-fire exposure of the finished goods.

o Reducing the initial oxygen volume fraction in the apparatus can affect the CO generation, but does not appear to affect the $\mathrm{HCl}$ generation. The effect of reduced initial oxygen volume fraction on HCN generation remains uncertain. Fitting the bench-scale test conditions to the full-scale fire ventilation conditions is likely to be important in obtaining good correlations of toxic gas generation.

\section{ACKNOWLEDGEMENTS}

The authors thank Michael Selepak for his assistance in performing specimen testing.

Certain commercial equipment, instruments, or materials are identified in this paper in order to specify the experimental procedure adequately. Such identification is not intended to imply recommendation or endorsement by the National Institute of Standards and Technology, nor is it intended to imply that the materials or equipment identified are necessarily the best available for the purpose. 


\section{REFERENCES}

[1] ISO 16312-2-2007, Guidance for Assessing the Validity of Physical Fire Models for Obtaining Fire Effluent Toxicity Data for Fire Hazard and Risk Assessment - Part 2: Evaluation of Individual Physical Fire Models, International Standards Organization, Geneva.

[2] NFPA 269 (2007), Standard test Method for Developing Toxic Potency Data for Use in Fire Hazard Modeling, National Fire Protection Association, Quincy, MA 02269.

[3] ASTM E1678-07, Standard Test Method for Measuring Smoke Toxicity for Use in Fire Hazard Analysis, ASTM International, West Conshohocken, PA, 19428.

[4] Kimmerle, G., "Aspects and Methodology for the Evaluation of Toxicological Parameters during Fire Exposure", (1974) Journal of Fire and Flammability Combustion Toxicology Supplement: 1, 4-51.

[5] Levin, B.C., Paabo, M., Gurman, J.L., and Harris, S.E., (1987) "Effects of Exposure to Single or Multiple Combinations of the Predominant Toxic Gases and Low Oxygen Atmospheres Produced in Fires," Fundamental and Applied Toxicology: 9, 236-250. doi:10.1016/0272-0590(87)90046-7

[6] Gann, R.G., Averill, J.D., Johnsson, E.L., Nyden, M.R., and Peacock, R.D., "Smoke Component Yields from Room-scale Fire Tests" National Institute of Standards and Technology Report NIST TN 1453, Gaithersburg, MD, 20899, 2003, 139 p.

[7] Levin, B.L., (1997) "New Approaches to Toxicity: A Seven-Gas Predictive Model and Toxicant Suppressants", Drug and Chemical Toxicology 4, 271-280. doi:10.3109/01480549709003885

[8] Haaland, D.M.; Easterling, R.G.; and Vopicka, D.A., (1985) "Multivariate Least-Squares Methods Applied to the Quantitative Spectral Analysis of Multicomponent Samples" Applied Spectroscopy 39, 73-84. doi:10.1366/0003702854249376

[9] Gas Phase Infrared Spectral Standards, Revision B, Midac Corp.; Irvine, CA (1999).

[10] Speitel, L.C., "Fourier Transform Infrared Analysis of Combustion Gases," Federal Aviation Administration Report DOT/FAA/AR-01/88, 2001. 